\title{
A Case of Patent Ductus Arteriosus with Aortic Stenosis
}

\section{KHURSHED AHMED, HARISULHOQUE, SM MUSTAFAZAMAN, FAKHRUL ISLAM KHALED, MD. ASHRAF UDDIN SULTAN, NILUFAR FATEMA, MSI TIPU CHOWDHURY, ADNAN BASHAR}

Department of Cardiology, Bangabandhu Sheikh Mujib Medical University, Dhaka

Address of Correspondence: Dr. Md. Khurshed Ahmed, Associate Professor, Department of Cardiology, University Cardiac Center, Bangabandhu Sheikh Mujib Medical University, Dhaka.E-mail: dmkahmed28@gmail.com

\begin{abstract}
:
Patent ductus arteriosus(PDA) is a congenital cardiac disorder which is not so uncommon but it becomes rare when associated with aortic stenosis. In our case clinical finding was consistent with PDA and aortic stenosis. Echocardiographic finding showed that patient also has moderate aortic regurgitation which makes this case one of the rarest.
\end{abstract}

Keywords: Patent ductus arteriosus (PDA), aortic stenosis, aortic regurgitation

University Heart Journal 2019; 15(2): 86-88

\section{Introduction:}

Patent ductus arteriosus (PDA) represents 5-10\% of all congenital heart lesions. ${ }^{1}$ Patients can present at any age. The typical child with a patent ductus arteriosus (PDA) is asymptomatic ${ }^{2}$. At times, the patient may report decreased exercise tolerance or pulmonary congestion in conjunction with a murmur ${ }^{1}$. Common association of PDA is coarctation of aorta. However, association of PDA with aortic stenosis beyond the neonatal period is unknown but appears to be extremely rare combination ${ }^{3}$. In this case report we are presenting a case of PDA with aortic stenosis.

\section{Case history:}

A 16 years old girl admitted for evaluation of dyspnoea and palpitation for 2 years. Dyspnoea is exertional, (NYHA class II), relieved by rest and not associated with cough, sputum, orthopnoea or PND. Palpitation is regular, rapid, related to exertion, not associated with chest pain or syncope. She had no previous history suggestive of rheumatic fever and endocarditis. She had repeated episodes of respiratory tract infection during childhood for which she visited several local physicians and got antibiotics for several times. Her birth history was uneventful.

General examination revealed patient was underweight. There was no cyanosis, clubbing, anaemia, jaundice. Her pulse was $60 \mathrm{~b} / \mathrm{min}$. Blood pressure was $100 / 40 \mathrm{mmHg}$ with wide pulse pressure. JVP was raised with prominent $v$ wave. Cardiovascular system examination revealed apex was shifted, lateral to the MCL in left $5^{\text {th }}$ ICS which was forceful and well sustained. Left parasternal heave was present. Systolic thrill was present in mitral, aortic, neck area and thrill in left infraclavicular region. $1^{\text {st }}$ heart sound was normal. $2^{\text {nd }}$ heart sound was not heard due to the presence of continuous murmur in infrascular space.

Ejection systolic murmur(grade 5) was present in aortic area radiating towards left neck. There was also a continuous murmur present at infraclavicular region

Other system examination was unremarkable.

Our provisional diagnosis was patent ductus arteriosus with aortic stenosis.

\section{Investigations:}

Patients $\mathrm{CBC}$ and biochemical tests were within normal limit.

ECG findings are consistent with left ventricular hypertrophy with strain pattern.

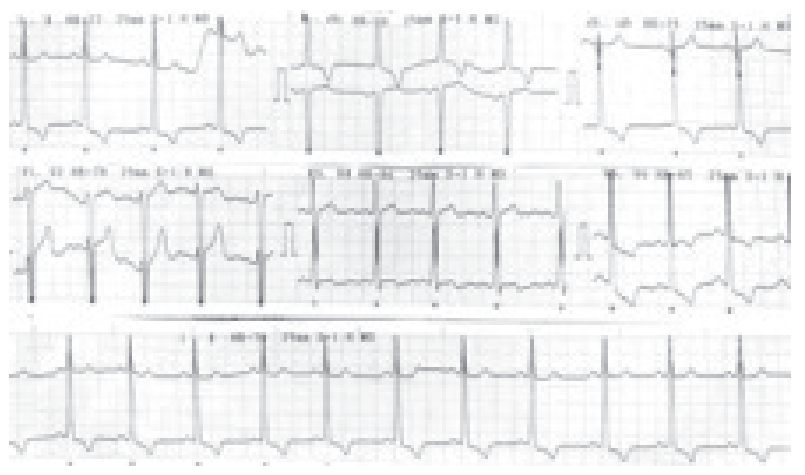

Fig.-1: ECG shows left ventricular hypertrophy with strain pattern. 
Chest X-ray showed increased transverse diameter of cardiac shadow with fullness of pulmonary conus. Pulmonary vascularity was also increased.

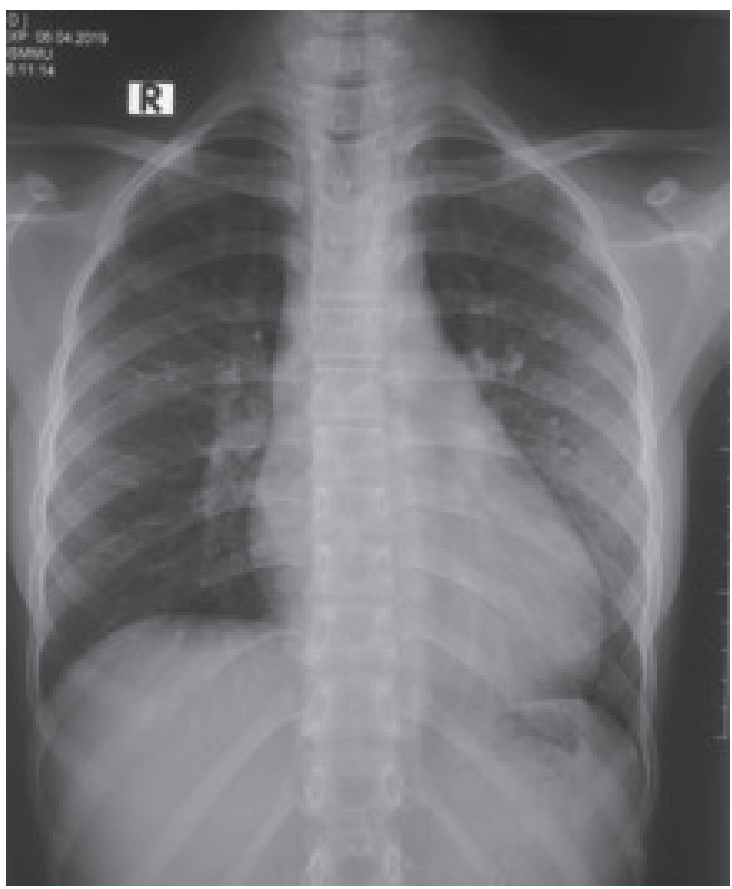

Fig.-2: $C X R P / A$ view shows cardiomegaly with fullness pulmonary conus.

2D guided M-mode echocardiography revealed concentric LV hypertrophy with normal function. The aortic valve consists of trileaflet and leaflets were mildly thickened. In modified PLAX view and suprasternal view with color flow showed connection between descending thoracic aorta and left pulmonary artery.

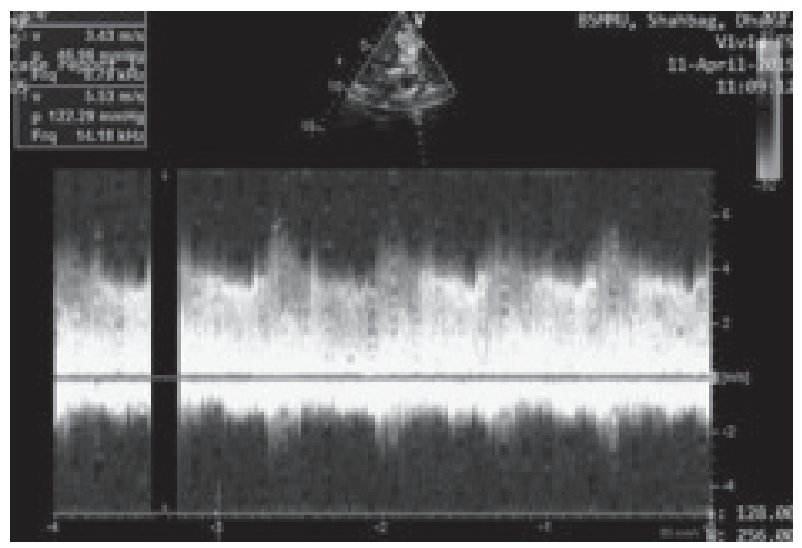

Fig.-3: Continuous wave Doppler tracing across the ductus.

Continuous wave Doppler examination across the ductus revealed continuous signal suggestive of PDA. Continuous wave Doppler at aortic valve level revealed

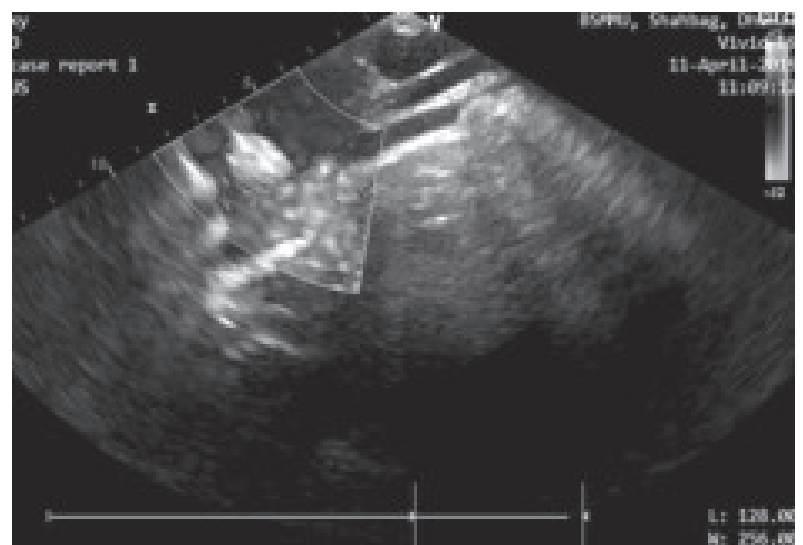

Fig.-4: Colour Doppler echocardiography showing presence of ductus

mean systolic gradient of $78 \mathrm{~mm} \mathrm{Hg}$. There was also moderate aortic regurgitation. The aorta to pulmonary artery systolic gradient was $122 \mathrm{~mm} \mathrm{Hg}$ and the diastolic gradient was $47 \mathrm{~mm} \mathrm{Hg.Qp} \mathrm{:} \mathrm{Qs} \mathrm{was} 2: 1$.

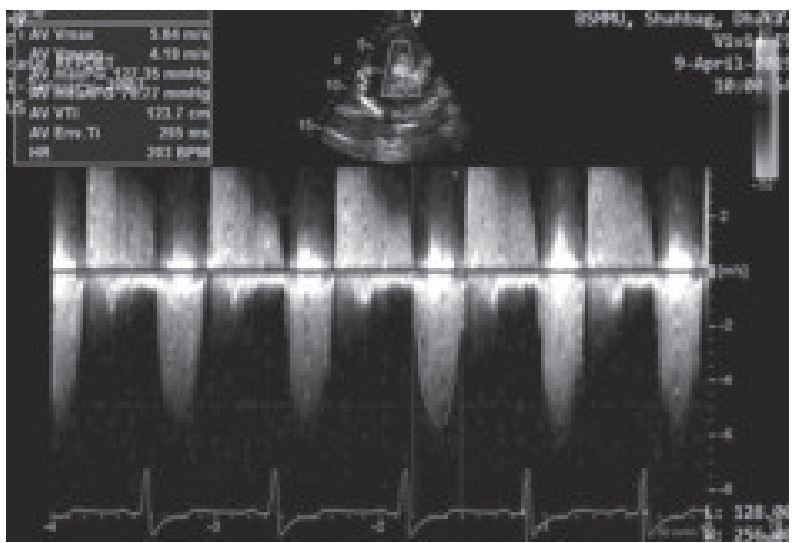

Fig.-5: Continuous Doppler echocardiography showing gradient across aortic valve

\section{Discussion:}

PDA is not uncommon congenital heart disease but combination of PDA with aortic stenosis is very rare. Whitlark JD et al found additional cardiac defects in 20 out of 146 patients referred for transcatheter closure of PDA among them only three patients had left ventricular outflow tract abnormality, two with a sub aortic membrane and one with a bicuspid aortic valve. ${ }^{4}$

This combination of PDA and aortic stenosis is so rare that only nine patient had undergone closure of PDA and aortic valve replacement till $1994 .^{4}$

In our case, though the aortic stenosis was severe but aortic valve was not proportionally diseased. One explanation of this is that in PDA there is volume overload in left side. So, the flow across the aortic valve is high. This is one of the major reason of increased systolic pressure gradient across the aortic valve. ${ }^{4}$ 
Regarding treatment purpose, it is better to close PDA first. So the flow across the aortic valve will decrease and thus there will be reduced gradient of the aortic valve. ${ }^{5}$

\section{Conclusion:}

PDA with aortic stenosis is one of the rare combinations. So, data regarding management of such condition is limited. PDA closure in such cases may decrease the severity of aortic stenosis.

\section{References:}

1. Luke K Kim, Jeffrey C Milliken. Patent DuctusArteriosus (PDA). https://emedicine.medscape.com/article/891096overview (accessed 24 May 2019)
2. TK Mishra, B Das, SN Routary, C Satpathy, HN Mishra. Congenital aortic stenosis and patent ductusarteriosus in an adult: A rare combination. Journal, Indian Academy of Clinical Medicine 2014; 15(1).

3. Gelb BD, O Laughlin MP, Mullins CE. Prevalence of additional cardiovascular anomalies in patients referred for transcatheter closure of patent ductusarteriosus. J Am CollCardiol 1990; 16: $1680-6$

4. Whitlark JD, Lazos JD, Visc JP. Combined aortic valve replacement and closure of patent ductusarteriosus in the elderly. J Card Surg 1994; 9: 85-8.

5. Glower DD, Bashore TM, Spritzer CE. Congenital aortic stenosis and patent ductusarteriosus in the adult. Ann ThoracSurg 1992; 54: 368-70. 